\title{
Mandibular Anterior Immediate Denture Using Visible Light Cure Acrylic
}

\author{
Amit A. Paryag1, Paul Seerattan², Reisha N. Rafeek ${ }^{3 *}$, Melissa S. Mankee ${ }^{4}$ \\ ${ }^{1}$ Fixed \& Removable Prosthodontics, School of Dentistry, The University of the West Indies, Mount Hope, \\ Trinidad \& Tobago \\ ${ }^{2}$ Removable Prosthodontics, School of Dentistry, The University of the West Indies, Mount Hope, Trinidad \& \\ Tobago \\ ${ }^{3}$ Restorative Dentistry, School of Dentistry, The University of the West Indies, Mount Hope, Trinidad \& Tobago \\ ${ }^{4}$ General Practitioner, D’Abadie, Trinidad \& Tobago \\ Email: *reisha.rafeek@sta.uwi.edu
}

Received 13 July 2015; accepted 22 November 2015; published 25 November 2015

Copyright (C) 2015 by authors and Scientific Research Publishing Inc.

This work is licensed under the Creative Commons Attribution International License (CC BY). http://creativecommons.org/licenses/by/4.0/

(c) (7) Open Access

\section{Abstract}

Management of a 51-year-old female of Afro Trinidadian descent required removal mandibular incisors. This patient's periodontal condition and her inability to afford pre-prosthetic surgery, bone grafting or even a fixed partial denture for replacement of the proposed units after extraction necessitated alternative treatment options to implants. Her profession required interaction with the public and as such an immediate replacement was essential. Impressions were taken and an immediate partial denture fabricated using a visible light cure acrylic. The mobile teeth were extracted and the denture delivered to the patient with minimal adjustments. The patient was monitored for three months while healing of the extraction site occurred and her periodontal condition was treated. Inability to afford definitive treatment for one year required the denture be maintained for that period. Follow up showed that the aesthetics, function and structural integrity of the denture had not been compromised.

\section{Keywords}

Visible Light Cure Acrylic, Removable Immediate Dentures

\section{Introduction}

One of the most important tasks facing dentists in general and prosthodontists in particular, is preserving as

\footnotetext{
${ }^{*}$ Corresponding author.
}

How to cite this paper: Paryag, A.A., Seerattan, P., Rafeek, R.N. and Mankee, M.S. (2015) Mandibular Anterior Immediate Denture Using Visible Light Cure Acrylic. Materials Sciences and Applications, 6, 1054-1060. 
much of the residual alveolar ridge as possible from the time of extracting the first tooth [1]. Post extraction, the dental team faces the challenge of creating a prosthetic restoration that blends with the adjacent natural dentition [2]. Functional and aesthetic prosthetic reconstructions are dependent on sufficient alveolar bone volume and favourable architecture of the alveolar ridge [2]. Within the past decade, as aesthetics have received more emphasis with treatment planning, resorption of the alveolar ridge following tooth extraction, especially in the anterior region has become a significant problem [3]. Major changes take place during the first twelve (12) months post extraction, with approximately two thirds of bony resorption occurring during the first 3 months of healing [4].

For many years, immediate dentures were considered to be a resorption-increasing factor [5]. It was believed that the denture insertion should occur after partial healing of the sockets and stabilization of the alveolar ridge. Comparative studies of patient groups have shown well-fitting dentures as a positive factor in the healing process [1]. A tendency for less resorption in cases provided with immediate-denture has been verified histologically [6].

Well-fitting immediate dentures rather than damaging bone may act as a bandage isolating the healing tissues from thermal and chemical damage and preventing food from entering the sockets [1]. Additionally they distribute masticatory forces over the healing area reducing trauma to the site while providing the patient with an interim aesthetic solution.

Visible light-cured (VLC) denture resins have become popular for many prosthodontic applications since the introduction of Triad VLC resin (Dentsply International, Inc., York, Pa.) including complete and removable partial denture relines, provisional fixed partial dentures, denture repairs, record bases, and custom impression trays [7]. Several investigations have been conducted into the physical properties and biocompatibility of VLC resin as well as its interaction with various relines materials and its bond strength to denture teeth [7]-[16]. Advantages of the Visible Light Cure (VLC) resin materials include ease of manipulation [16] good physical properties, absence of free methyl methacrylate, and low exothermic reaction heat [8] [9]. It exhibits greater [10] or at least comparable [12] transverse strength and micro-hardness as compared to conventional denture based acrylic resin. Comparison of its mechanical properties to other polymers [11], and investigations into its interaction with various relines materials [13] [14] and its bond strength to denture teeth [7] have also been conducted. It has also been used in fabricating a hollow obturator [17]. The use of VLC acrylic in this case enabled the practitioner to fabricate an immediate denture in a relatively short space of time. The following report outlines the management of a patient using VLC resin in the fabrication of an immediate denture in the anterior mandible.

\section{Case History}

A 51-year-old female of Afro Trinidadian descent presented to the authors' private practice for removal of a mobile maxillary first molar. There were no findings of clinical significance in her medical history. She was a customer service representative. The patient was a non-smoker and consumed alcohol socially less than once a month. She had attended the dentist irregularly since having her initial restorative work. She had never had scaling or root planing done.

Extra-oral examination revealed no findings of clinical significance. Intra-oral examination revealed the presence of mobile teeth including maxillary first molar (Grade 3 mobility) and mandibular incisors (Grade 3 on left central and lateral incisors and right central incisor. A non-tender, fluctuant, swelling was observed in the apical region of the mandibular incisors (Figure 1 and Figure 2). A purulent discharge was observed draining from the gingival sulcus around the lower incisors upon compression of the swelling.

Radiographic examination revealed greater than $75 \%$ bone loss around three of the mandibular incisors (Figure 3). Upon completion of the examinations a diagnosis of Generalized Chronic Periodontitis was determined. The prognosis of teeth numbers 31, 32 and 41 was deemed hopeless. Appropriate management required removal of these teeth. Various treatment options were formulated and presented to the patient (Table 1).

The patient selected Option 3 of a Visible Light Cured (VLC) acrylic immediate partial denture for replacement of the mandibular incisors during the healing and stabilization phase. It was decided that after her three month review a decision would be made to either monitor and continue with her maintenance phase (during which time the VLC denture could be relined with traditional heat cured acrylic), or progress to more advanced restorative therapy. 


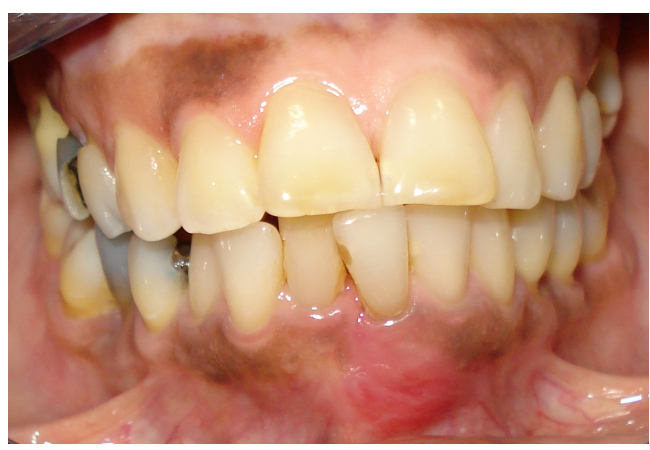

Figure 1. Anterior buccal view with a swelling near lower left central incisor.

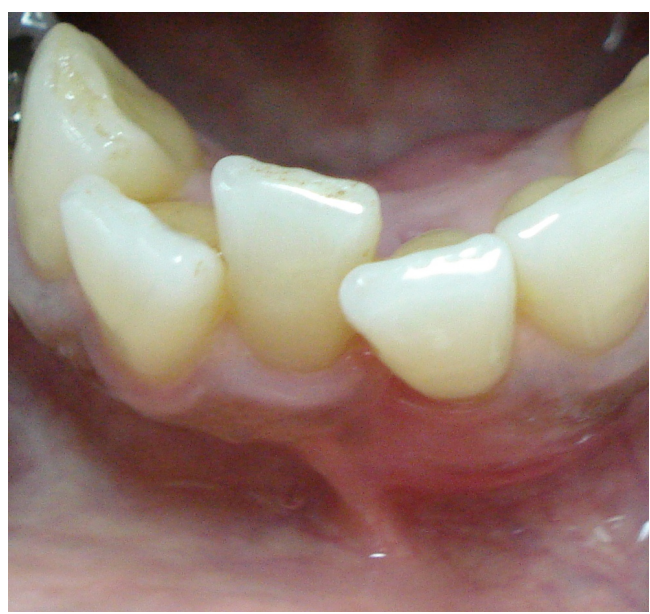

Figure 2. Occlusal view of lower anteriors.

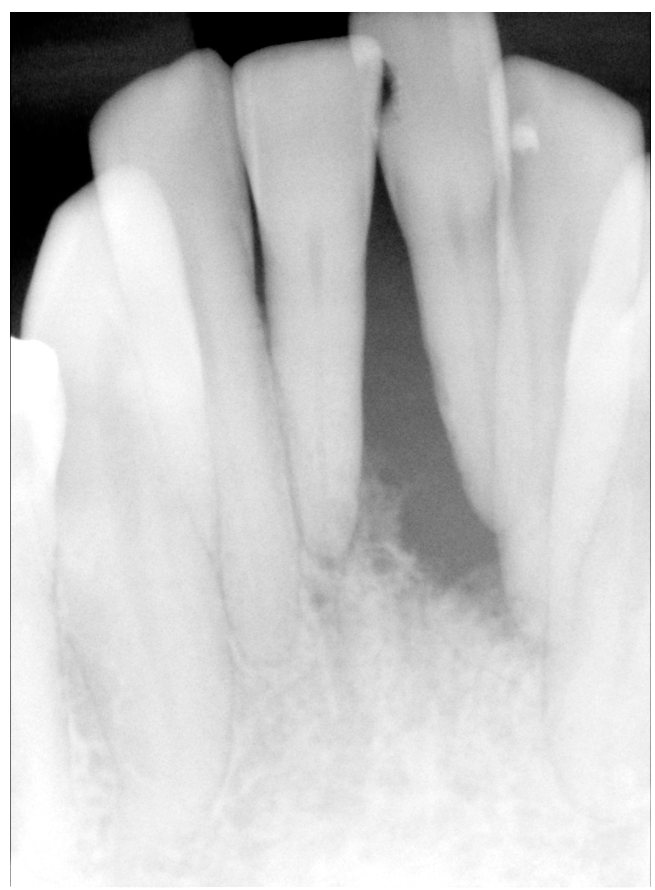

Figure 3. Periapical radiograph of lower anteriors. 
Impressions were taken of both maxilla and mandible using irreversible hydrocolloid (Alginate, Impression Material, Henry Schein Inc. Melville, NY) in plastic stock trays and poured immediately in Type III dental stone. After trimming, the study casts were soaked in water, the teeth to be removed in the anterior mandible were marked in pencil and removed with a fret saw and the area refined with a \#15 scalpel blade.

Wire clasps for retention were fabricated out of seven (7) gauge Stainless Steel wire and secured to the cast with wax on the buccal surface of the mandibular premolars. The cast was coated in "Die Lube" (Dentsply Ceramco, Dentsply International Inc. York, PA) to act as a separating agent. A sheet of TRIAD VLC Denture Base Material was then adapted to the lingual aspect of the anterior mandible with care being taken to cover the clasps adequately. Teeth of shade Myerson $\mathrm{F}$ were added to the base and the occlusion checked. The adaptation of the material was double checked and the area around the gingival margin was festooned using VLC denture base material (Figure 4).

The denture and cast were then placed in the TRIAD 2000 Visible Light Cure System (Dentsply International Inc. York, PA) oven for 6 minutes. After this time the denture was removed from the cast and a replaced in the oven for a further 2 minutes (Figure 5).

After curing the denture was trimmed with an acrylic bur in a straight nose hand-piece to remove any excess and then polished on a lathe to achieve acceptable smoothness (Figure 6).

Following fabrication of the denture, the patient was recalled and anesthetized using 1 carpule of Articaine $4 \%$. The mobile teeth were extracted, the extraction sites sutured and the denture delivered to the patient with minimal adjustments (Figure 7 and Figure 8).

The patient was reviewed one (1) week later and the sutures removed since adequate healing was observed. She was then monitored for three months while healing of the extraction site occurred and her periodontal condition was treated.

At the three-month review, the tissues were found to be healing appropriately. The denture exhibited no signs of fracture and there appeared to be no decrease in the bond strength of the acrylic teeth to the denture base. The denture was relined at chair-side with hard denture reline material and it was proposed that monitoring for a further three (3) months be done while the patient accumulated sufficient funds to embark on a more definitive restoration for replacing the missing mandibular dentition. The patient was unable to afford definitive treatment for one year and as such maintained the denture for that period. Follow up after one year showed that the aesthetics, function and structural integrity of the denture had not been compromised (Figure 9).

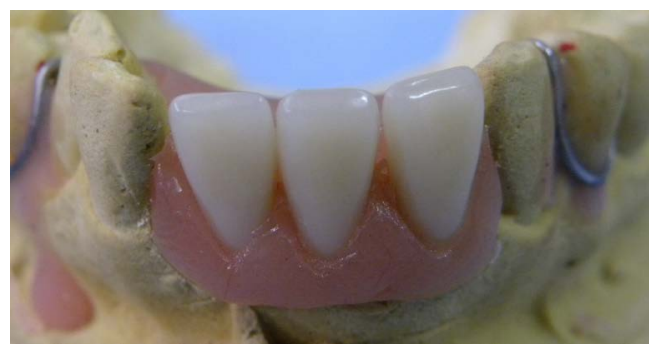

Figure 4. Anterior view of lower model with VLC denture.

Table 1. Treatment options available for patient for the anterior mandibular region.

Option 1:

Heat cured acrylic partial denture for immediate replacement of teeth in the anterior mandible.

Soft reline after initial healing followed by permanent hard reline.

Option 2:

Heat cured acrylic partial transitional denture for immediate replacement of teeth in the anterior mandible

Soft reline during initial healing followed by hard reline after 3 - 6 weeks.

Fabrication of a Cobalt Chrome (Co-Cr) lower denture to replace all missing units after adequate bone healing e.g. 4 months

Option 3:

Visible Light Cured acrylic partial denture for immediate replacement of teeth in the anterior mandible

Reline of VLC denture after 3 months while stabilization of periodontal condition occurs.

Review for decision for definitive treatment option-Implants, Fixed Prosthesis or Removable Co-Cr prosthesis. 


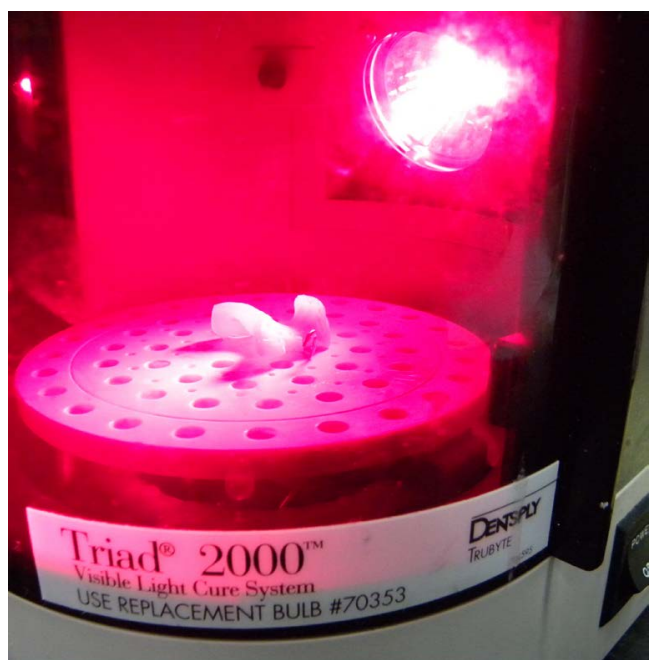

Figure 5. The denture and cast in the TRIAD 2000 visible light cure system.

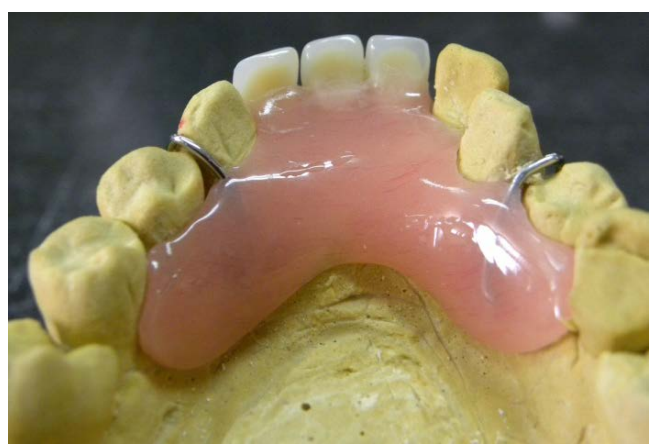

Figure 6. Lingual view of VLC denture trimmed and polished on model.

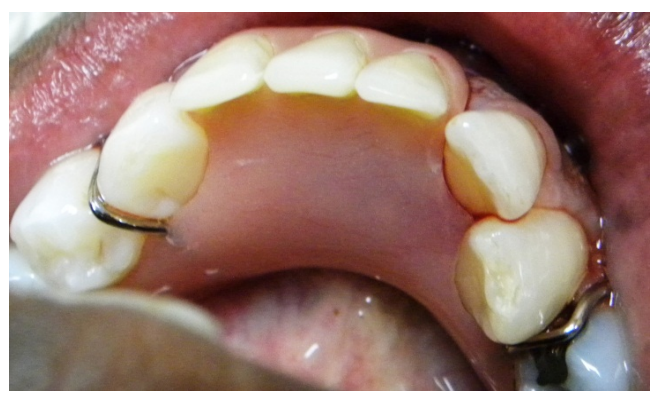

Figure 7. Lingual view of VLC denture fitted on patient after extractions.

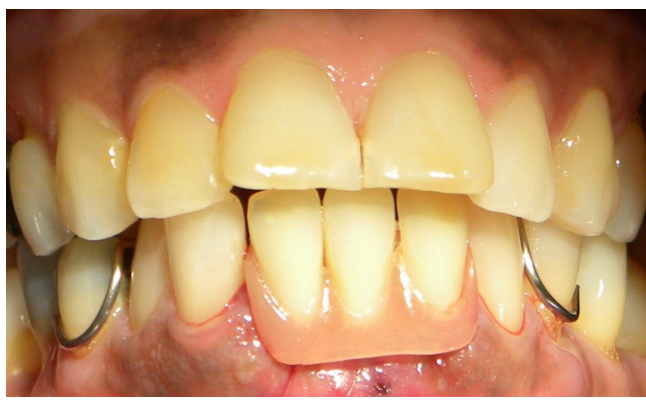

Figure 8. Anterior buccal view of VLC denture fitted. 


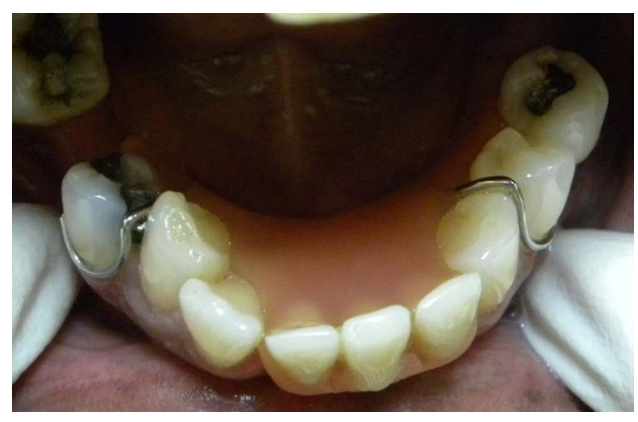

Figure 9. VLC denture after 1 year review.

\section{Discussion}

After comprehensive examination of this patient it was determined that stabilization of the patient's periodontal condition and adequate healing of the extraction sites after removal of the hopeless teeth were imperative before commencing any form of advanced restorative treatment such as implants, or fixed prosthesis. Her inability to afford a provisional fixed partial denture for replacement of the proposed units after extraction necessitated an alternative treatment option. Additionally her profession required interaction with the public and as such an immediate replacement was essential.

Advantages of the VLC resin materials include ease of manipulation, good physical properties, absence of free methyl methacrylate, and low exothermic reaction heat [8]. The bond strength of Triad VLC reline material to the tested denture base resins is sufficiently high to suggest its clinical applicability as a direct intraoral relining of complete and removable partial dentures [15]. These characteristics make it a potentially useful material in the fabrication of an immediate partial denture either chair-side or rapidly in a laboratory setting. Potential contraindications include lower bond strength to denture teeth as compared to heat-cured acrylic [8], and a shorter lifespan than traditional heat cured immediate partial dentures.

The use of VLC acrylic in this case enabled the practitioner to fabricate an immediate denture in a relatively short space of time. The patient was well aware of the potential drawbacks such as fracture and debonding of teeth but felt that the difference in cost when compared to a traditional acrylic denture was worth having this alternative made. Additionally since the denture would be used for only a period of three (3) months while healing occurred at the extraction sites, and relining of this material chair-side is possible, the option was utilized to good effect.

\section{Summary}

The patient presented with localized chronic periodontitis around the anterior mandibular teeth. Extraction of these teeth was deemed necessary. Impressions were done with irreversible hydrocolloid (Alginate) and study casts fabricated teeth to be extracted were sectioned off the cast and Visible Light Cure Acrylic was used to fabricate an immediate denture.

The denture was delivered on extraction of the teeth and the patient monitored for a period of 3 months during healing of the extraction sites and while stabilization of the periodontal condition occurred. Follow up after one year showed that the aesthetics, function and structural integrity of the denture had not been compromised.

\section{References}

[1] Wictorin, L. (1969) An Evaluation of Bone Surgery in Patients with Immediate Dentures. Journal Prosthetic Dentistry, 21, 6-13. http://dx.doi.org/10.1016/0022-3913(69)90026-2

[2] Van der Weijden, F., Dell'Acqua, F. and Slot, D.E. (2009) Alveolar Bone Dimensional Changes of Post-Extraction Sockets in Humans: A Systematic Review. Journal of Clinical Periodontology, 36, 1048-1058. http://dx.doi.org/10.1111/j.1600-051X.2009.01482.x

[3] Bartee, B.K. (2001) Extraction Site Reconstruction for Alveolar Ridge Preservation. Part 1: Rationale and Materials Selection. Journal of Oral Implantology, 27, 187-193. http://dx.doi.org/10.1563/1548-1336(2001)027<0187:ESRFAR>2.3.CO;2

[4] Schropp, L., Wenzel, A., Kostopoulos, L. and Karring, T. (2003) Bone Healing and Soft Tissue Contour Changes Fol- 
lowing Single-Tooth Extraction: A Clinical and Radiographic 12-Month Prospective Study. International Journal of Periodontology and Restorative Dentistry, 23, 313-323.

[5] Campbell, R.L. (1960) A Comparative Study of the Resorption of the Alveolar Ridges in Denture-Wearers and NonDenture-Wearers. Journal of the American Dental Association, 60, 143-153. http://dx.doi.org/10.14219/jada.archive.1960.0031

[6] Carlsson, G.E., Thilander, II. and Hedegard, B. (1967) Histological Changes in the Upper Alveolar Process after Extractions with or without Insertion of an Immediate Full Denture. Acta Odontologica Scandinavia, 25, 21-43. http://dx.doi.org/10.3109/00016356709072521

[7] Clancy, J.M.S., Hawkins, F.L., Keller, J.C. and Boyer, D.B. (1991) Bond Strength and Failure Analysis of Light-Cured Denture Resins Bonded to Denture Teeth. Journal Prosthetic Dentistry, 65, 316-324. http://dx.doi.org/10.1016/0022-3913(91)90182-V

[8] Clancy, J.M.S. and Boyer, D.B. (1989) Comparative Bond Strength of Light-Cured, Heat-Cured, and Autopolymerizing Denture Resins to Denture Teeth. Journal Prosthetic Dentistry, 61, 457-462. http://dx.doi.org/10.1016/0022-3913(89)90014-0

[9] Ogle, R.E., Sorenson, S.E. and Lewis, E.A. (1986) A New Visible Light-Cured Resin System Applied to Removable Prosthodontics. Journal Prosthetic Dentistry, 56, 497-506. http://dx.doi.org/10.1016/0022-3913(86)90397-5

[10] Khan, Z., van Fraunhofer, J.A. and Razavi, R. (1987) The Staining Characteristics, Transverse Strength, and Microhardness of a Visible Light-Cure Denture Material. Journal Prosthetic Dentistry, 57, 384-386. http://dx.doi.org/10.1016/0022-3913(87)90319-2

[11] Ishigama, K., Mashio, T., Tsukui, J., Umi, T., Maeda, M., Iwachi, N., Ujhe, Y., Satoh, Y., Anzai, M. and Ohki, K. (1987) Basic Studies on Visible Light-Curing Resin as a Denture Base. Journal of Nihon University School of Dentistry, 29, 35-41. http://dx.doi.org/10.2334/josnusd1959.29.35

[12] Lewinstein, I., Zeltser, C.M., Mayer, C.M. and Tal, Y. (1995) Transverse Bond Strength of Repaired Acrylic Resin Strips and Temperature Rise of Dentures Relined with VLC Reline Resin. Journal Prosthetic Dentistry, 74, 392-399. http://dx.doi.org/10.1016/S0022-3913(05)80380-4

[13] Arena, C.A., Evan, D.B. and Hilton, T.J. (1993) A Comparison of Bond Strengths among Chairside Hard Reline Materials. Journal Prosthetic Dentistry, 70, 126-131. http://dx.doi.org/10.1016/0022-3913(93)90006-A

[14] Khan, Z., Martin, J. and Collard, S. (1989) Adhesion Characteristics of Visible Light-Cured Denture Base Material Bonded to Resilient Lining Materials. Journal Prosthetic Dentistry, 62, 196-200. http://dx.doi.org/10.1016/0022-3913(89)90313-2

[15] Razavi, R., Khan, Z. and von Fraunhofer, J.A. (1990) The Bond Strength of a Visible Light-Cured Reline Resin to Acrylic Resin Denture Base Material. Journal of Prosthetic Dentistry, 63, 485-487. http://dx.doi.org/10.1016/0022-3913(90)90243-6

[16] Machado, C., Sanchez, E., Azer, S.S. and Uribe, J.M. (2007) Comparative Study of the Transverse Strength of Three Denture Base Materials. Journal of Dentistry, 35, 930-933. http://dx.doi.org/10.1016/j.jdent.2007.09.006

[17] Kocacikli, M., Yalug, S., Yazicioglu, H. and Yilmaz, C. (2008) Fabricating a Hollow Obturator with Visible LightCured Resin System. Journal of Prosthodontics, 17, 596-598. http://dx.doi.org/10.1111/j.1532-849X.2008.00335.x 